\title{
The Implication of the Polymorphisms of COX-1, UGT1A6, and CYP2C9 among Cardiovascular Disease Patients Treated with Aspirin
}

\author{
Nur Jalinna Abdul Jalil ${ }^{1}$, Zakaria Bannur ${ }^{1}$, A. Derahman ${ }^{1}$, O. Maskon ${ }^{2}$, Noor Darinah ${ }^{2}$, Hamat Hamidi ${ }^{2}$, Osama Ali $^{2}$, \\ Gunasekaran ${ }^{2}$, Mohd Rafizi ${ }^{2}$, Nur Izatul Azreen ${ }^{2}$, Teh Lay Kek ${ }^{1,3}$, Mohd Zaki Salleh ${ }^{1,3}$ \\ ${ }^{1}$ Integrative Pharmacogenomics Institute (iPROMISE), Universiti Teknologi MARA (UiTM), Bandar Puncak Alam, 42300 \\ Selangor, Malaysia; ${ }^{2}$ University Kebangsaan Malaysia Medical Centre, Cheras 56000, Kuala Lumpur, Malaysia.; ${ }^{3}$ Faculty \\ of Pharmacy, Universiti Teknologi MARA (UiTM), Bandar Puncak Alam, 42300 Selangor, Malaysia.
}

Received, April 3, 2015; Revised, August 9, 2015; Accepted, September 18, 2015; Published, September 30, 2015

\begin{abstract}
Purpose. Enzymes potentially responsible for the pharmacokinetic variations of aspirin include cyclooxygenase-1 (COX-1), UDP-glucuronosyltransferase (UGT1A6) and P450 (CYP) (CYP2C9). We therefore aimed to determine the types and frequencies of variants of COX-1 (A-842G), UGT1A6 (UGT1A6*2; $A 541 G$ and $U G T 1 A 6 * 3 ; A 522 C)$ and CYP2C9 $(C Y P 2 C 9 * 3 ; A 1075 C)$ in the three major ethnic groups in Malaysia. In addition, the role of these polymorphisms on aspirin-induced gastritis among the patients was investigated. Methods: A total of 165 patients with cardiovascular disease who were treated with $75-150 \mathrm{mg}$ daily dose of aspirin and 300 healthy volunteers were recruited. DNA was extracted from the blood samples and genotyped for COX-1 (A-842G), UGT1A6 (UGT1A6*2 and UGT1A6*3) and CYP2C9 (CYP2C9*3;A1075C) using allele specific polymerase chain reaction (AS-PCR). Results: Variants $U G T 1 A 6 * 2, * 3$ and $C Y P 2 C 9 * 3$ were detected in relatively high percentage of $22.83 \%, 30.0 \%$ and $6.50 \%$, respectively; while $C O X-1(A-842 G)$ was absent. The genotype frequencies for $U G T 1 A 6 * 2$ and $* 3$ were significantly different between Indians and Malays or Chinese. The level of bilirubin among patients with different genotypes of UGT1A6 was significantly different ( $p$-value < 0.05). In addition, $C Y P 2 C 9 * 3$ was found to be associated with gastritis with an odd ratio of 6.8 (95\% Cl OR: 1.39 - 33.19; $P=0.033$ ). Conclusion: Screening of patients with defective genetic variants of UGT1A6 and $C Y P 2 C 9 * 3$ helps in identifying patients at risk of aspirin induced gastritis. However, a randomised clinical study of bigger sample size would be needed before it is translated to clinical use.
\end{abstract}

Keywords: $C O X-1$, UGT1A6, $C Y P 2 C 9$, Aspirin

What This Study Adds: Genotyping Screening for $U G T 1 A 6 * 2, U G T 1 A 6 * 3$ and $C Y P 2 C 9 * 3$ helps to identify patients at risk of aspirin induced gastritis.

This article is open to POST-PUBLICATION REVIEW. Registered readers (see "For Readers") may comment by clicking on ABSTRACT on the issue's contents page.

\section{INTRODUCTION}

Aspirin with a dose of $75-150 \mathrm{mg}$ daily has been found to reduce risk of vascular events by approximately $32 \%$ in patients with cardiovascular disease (CVD) [1]. However, a substantial number of patients do not respond optimally to aspirin treatment [2]. The inter-individual variability of patients' responses is due to variation either in pharmacokinetic (PK) or pharmocodynamic (PD) properties of aspirin [3]. Those polymorphic enzymes potentially affecting the PK-PD of aspirin include cyclooxygenase-1 (COX-1), UDPglucuronosyltransferase 1A6 (UGT1A6) and CYP2C9 enzymes.
COX-1 is directly and irreversibly inhibited by aspirin resulting in reduction or inhibition of the formation of precursors of prostaglandins and thromboxanes. Genetic variants of $C O X-1$ gene were suggested to modulate arachidonic acidinduced platelet aggregation and serum thromboxane B2 (TXB2) levels in patients treated with aspirin. The Polymorphic UDPglucuronosyltransferase (UGT1A6) and CYP2C9*3

\footnotetext{
Correspondence Authors: Dr. Mohd Zaki Salleh, \& Dr. Teh Lay Kek, Integrative Pharmacogenomics Institute, Universiti Teknologi MARA, Malaysia. zakisalleh@puncakalam.uitm.edu.my; tehlaykek@gmail.comMalaysia.
} 
enzymes are reported to be associated with altered enzyme function which affects aspirin metabolism and efficacy. . The amino acid changes for two variants of UGT1A6 (UGT1A6*2;A541G and UGT1A6*3; A522C) result in a $30 \%-50 \%$ reduced enzyme activity compared to enzyme encoded by the wild-type allele [4]. Both variants of UGT1A6*2 and $* 3$ are in complete linkage disequilibrium [5]. The variant alleles for $C Y P 2 C 9 * 3$ also produce enzymes bearing some $5 \%-30 \%$ of the activity of the wild-type enzyme [6]. All these polymorphic enzymes might modulate the therapeutic effect of aspirin in treatment or prevention of CVD. Carriers of variant alleles are more prone to develop acute gastrointestinal problems when they receive aspirin as compared to non-carriers $[7,8]$.

Several biochemical tests are routinely screened among the patients in order to assess the risk of early stage CVD. Altered Lipid profiles which includes HDL, LDL, trigylcerides and total cholesterol are common risk factors for CVD. The higher the cholesterol level, the higher the risk of CVD disease. However, HDL is "good cholesterol" which protects one against the disease by removing cholesterol and excess fat from blood vessel walls and transports them to the liver to be removed from the body. Besides, there is an apparent protective effect of bilirubin which is in similar magnitude as HDL. A study shows that a $50 \%$ decrease in total bilirubin was associated with a $47 \%$ increased risk of having more severe coronary artery disease $(p=0.02)$ [9]. Since, UDP-glucuronosyltransferase (UGT1A6) is highly expressed in liver and plays a major role in the metabolisms of bilirubin, their genetic polymorphisms and bilirubin levels are potentially important risk factors of CVD.

The aims of this study were to investigate the relationship between the clinical parameters and genetic polymorphisms of COX-1, UGT1A6 and $C Y P 2 C 9$ in cardiovascular patients. This allows the assessment of the impact of genetic polymorphisms of COX-1, UGT1A6 and CYP2C9 on gastritis or other gastrointestinal symptoms in cardiovascular patients treated with aspirin.

\section{METHODS}

\section{Subjects}

The protocol of the study was approved by the local Research and Ethics Committee. The study comprised of 165 patients and 300 healthy volunteers aged 18 to 65 years old. All patients were diagnosed with cardiovascular disease and treated with aspirin (acetylsalicylic acid, 75-150 mg daily dose); while the healthy volunteers were unrelated individuals not receiving any treatment. All the participants were healthy mentally and physically, understand the study protocol and willing to sign the consent form.

\section{Data Collection}

Medical records for all patients were reviewed. The clinical data include medical history, biochemical test result (i.e. liver function test, renal function test, full blood count, lipid profile and blood glucose), dosage regimen, INR measurement, concurrent drugs intake and adverse effects experienced by patients were recorded. Sign and symptoms of gastritis such as gastric pain, vomiting and loss of appetite were reviewed and diagnosed by the medical doctors in charged.

\section{Genotyping}

Five milliliters of blood samples were drawn into tubes which contained tri-sodium citrate $(4 \%)$. The blood samples were used for DNA extraction and genotyping for variants of UGT1A6, COX-1 and CYP2C9. The DNA was extracted using lysis method that has been optimized previously [10]. The extracted DNA was dissolved in 1x TE buffer and kept at $-20{ }^{\circ} \mathrm{C}$ freezer until use. Allele specific PCR (AS-PCR) method was developed for detection of each variant. This technique is based on single-nucleotide variations which introduced destabilizing mismatch at the 3 ' end of the allelespecific primers [11].

A nested PCR was developed to amplify COX-1(A-842G) variants. Amplicon sizes for the first step PCR and allele specific $C O X-1(A-842 G)$ variant are $369 \mathrm{bp}$ and $150 \mathrm{bp}$, respectively. The optimal primer concentrations used was $0.2 \mu \mathrm{M}$ for common forward (5'GGTGATCTTGGACCTATTCC-3') and reverse (5'-CTTGGACAAGGTACTTATCTT-3') primers; $0.3 \mu \mathrm{M}$ for variant (5'GCACCTACTACATGCTGTG -3') and wild-type (5'- GCACCTACTACATGCTGTA-3') primers. The thermal cycling condition comprised of 30 cycles of $1^{\text {st }}$ step and 15 cycles for the $2^{\text {nd }}$ step PCR reaction. DNA denaturing was set at temperature of $94^{\circ} \mathrm{C}$ for 30 seconds, while annealing and extension steps were set at $50^{\circ} \mathrm{C}$ for 30 seconds and $72^{\circ} \mathrm{C}$ for 
30 seconds, respectively. Fragments of PCR product are shown in Figure 1(a) $\left(2^{\text {nd }}\right.$ step).

One set of forward and reverse primers flanking $150 \mathrm{bp}$ of Beta-2-microglobulin (B2M) gene was used as the internal control. The sets of primers used for detection of $U G T 1 A 6 * 2(A 541 G)$ variant were forward primer, 5'CGATCATTCCTAACTGCTCCTC-3', $0.2 \mu \mathrm{M}$; reverse primer, 5'- TGGGCTTCTGCTGAATGC 3', $0.3 \mu \mathrm{M}$ ); and wild-type (forward primer, 5'CGATCATTCCTAACTGCTCCTC-3', $0.2 \mu \mathrm{M}$; Reverse primer, 5' - TGGGCTTCTGCTGAATGT 3', $0.3 \mu \mathrm{M})$. For determination of UGT1A6*3 (A522C), the primers used were forward primer, 5'CGATCATTCCTAACTGCTCCTC-3', $0.2 \mu \mathrm{M}$; reverse primer, 5'- GGAGCATACATTCAGCAGC -3 '; $0.3 \mu \mathrm{M}$ and wild-type forward primer, 5'CGATCATTCCTAACTGCTCCTC-3', $0.2 \mu \mathrm{M}$; reverse primer, 5'- GGAGCATACATTCAGCAGA -3 $0.3 \mu \mathrm{M}$. The fragment size of amplicons for variant detection of $U G T 1 A 6 * 2$ (A541G) and $U G T 1 A 6 * 3$ (A522C) are $255 \mathrm{bp}$ and $301 \mathrm{bp}$, respectively. The thermal cycling conditions for UGT1A6 variants are the same as COX-1 except for the annealing temperature. DNA was denatured at temperature of $94^{\circ} \mathrm{C}$ for 30 seconds, while annealing temperature for $U G T 1 A 6 * 2$ and $* 3$ are $54^{\circ} \mathrm{C}$ and $60^{\circ} \mathrm{C}$, respectively. The extension steps were set at $72^{\circ} \mathrm{C}$ for 30 seconds. The fragments of PCR products for both polymorphisms are shown in Figure 1(b) UGT1A6*2 and Figure 1 (c) UGT1A6*3.

For $C Y P 2 C 9 * 3$, the amplified fragments for internal control and allele specific are $250 \mathrm{bp}$ and $470 \mathrm{bp}$, respectively (Figure 1 (d)). The fragments were amplified using specific primers (variants type forward primer, 5' - CGAGGTCCAGAGATACC3', $\quad 0.3 \mu \mathrm{M}$; $\quad$ reverse primer, 5'CCTCAACGTGTCAAGATTCAGT-3', $0.2 \mu \mathrm{M}$ ); and wild-type forward primer, 5'CGAGGTCCAGAGATACA-3', $0.3 \mu \mathrm{M}$; reverse primer, 5'-CCTCAACGTGTCAAGATTCAGT-3', $0.2 \mu \mathrm{M})$. The thermal cycling conditions were the same as for amplification of variants of $C O X-1$ and UGT1A6, but the optimum annealing temperature was $55^{\circ} \mathrm{C}$. For confirmation of the results, PCR products for each variants were sequenced using direct sequencing approach. The sequencing results are illustrated in Figure 1.

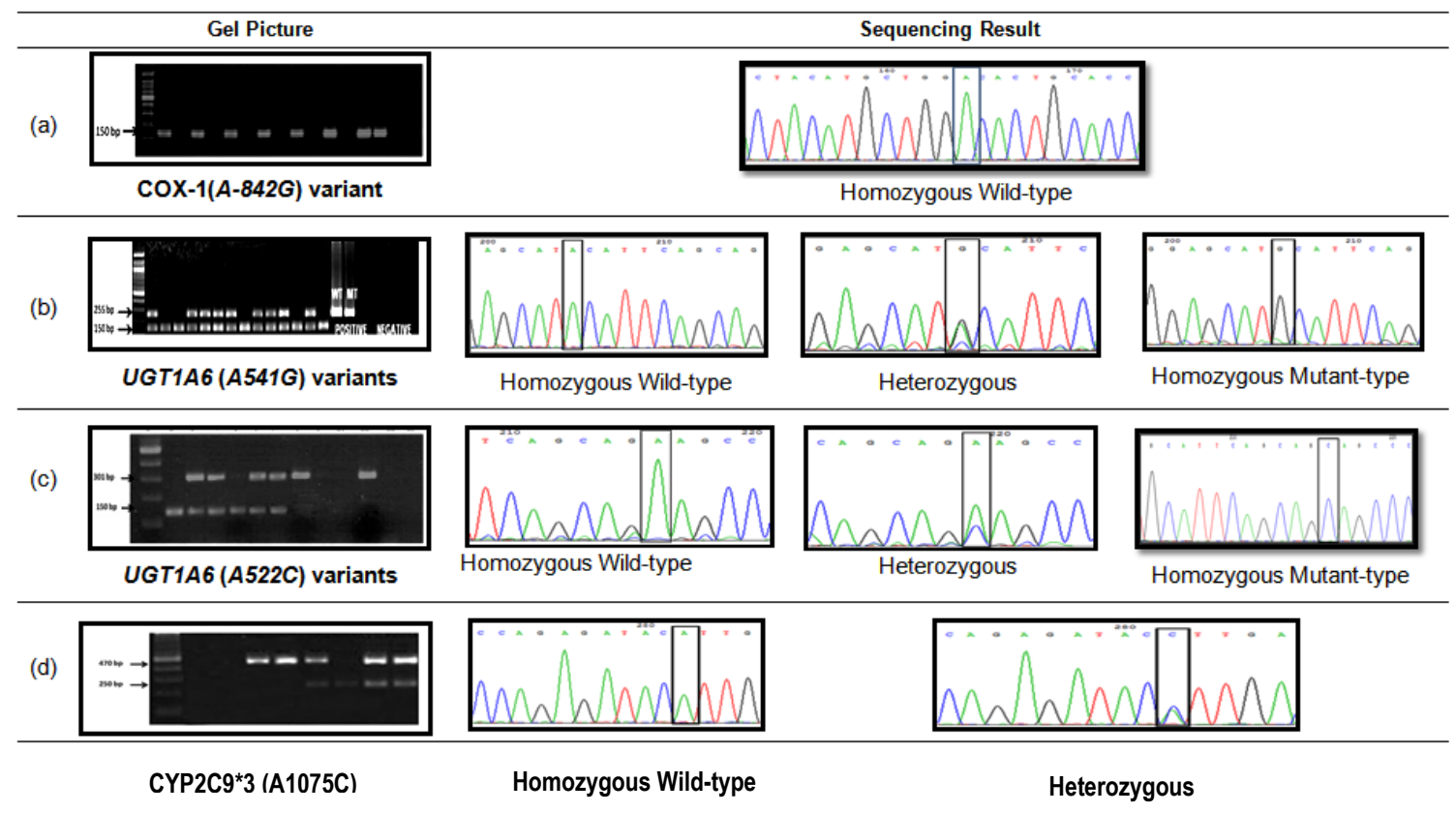

Figure 1. Nucleotide Sequence of the PCR Products of COX-1(A-842G), UGT1A6 (A541G and $A 522 C$ ) and $C Y P 2 C 9 * 3$ (A1075C) Allele 


\section{Data Analysis}

The genotypes and allelic frequencies of $C O X-1$, UGT1A6 and $C Y P 2 C 9 * 3$ were analyzed. Statistical analysis was carried out using Statistical Package for Social Science (SPSS), version 20. The observed and expected genotype frequencies were compared. Chi-square test was used to evaluate the fitness of the genotypic distribution to HardyWeinberg equilibrium. Numerical variables such as age, BMI, bilirubin and albumin were analyzed using Independent t-test, Mann- Whitney or Kruskal-Wallis test when appropriate. Categorical variants such as ethnicity and gender were analyzed using Chi-square test. For UGT1A6 gene, the patterns of linkage disequilibrium (LD) for both SNPs (A541G and A522C) were analyzed and visualized, pair-wise of both SNPs were computed using Haploview (SNPs Tools) (http://www.bioinformatics.org/snp-tools-excel) [12]. The relative risk of aspirin induced gastritis due to genetic variant was tested using odd ratio (OR) (http://www.medcalc.org/calc/odds_ratio.php).

\section{RESULTS}

Three hundred healthy volunteers, 100 each of Malays, Chinese and Indians were recruited. A total number of 165 patients with cardiovascular disease (CVD) who met the inclusion and exclusion criteria of the study were also recruited. Most of the CVD patients were male $(84.52 \%)$ and the remaining were female $(15.48 \%)$. About $86.67 \%$ of the total patients were overweight and most of them were smokers $(59.39 \%) ; 75.15 \%$ of the patients have dyslipidaemia (Table 1).

Table 1. Demographic and Clinical Data of the CVD Patients (Categorical variables)

\begin{tabular}{|c|c|c|c|c|c|c|}
\hline \multirow{2}{*}{ Variable } & & \multirow{2}{*}{$\begin{array}{l}\text { n } \\
(165)\end{array}$} & \multicolumn{2}{|l|}{ Gender } & \multirow{2}{*}{$\begin{array}{c}\% \\
(100)\end{array}$} & \multirow[b]{2}{*}{$p$} \\
\hline & & & Male & Female & & \\
\hline \multirow{3}{*}{ Ethnicity } & Malays & 69 & $62(89.9 \%)$ & $7(10.1 \%)$ & 41.82 & \multirow{3}{*}{$<0.001^{*}$} \\
\hline & Chinese & 73 & $58(79.5 \%)$ & $15(20.5 \%)$ & 44.24 & \\
\hline & Indian & 23 & $20(87.0 \%)$ & $3(13.0 \%)$ & 13.94 & \\
\hline \multirow{2}{*}{ BMI } & Normal $(\leq 24.99)$ & 22 & $22(100 \%)$ & $0(0.0 \%)$ & 13.33 & \multirow{2}{*}{$<0.001 *$} \\
\hline & Overweight $(\geq 25.00)$ & 143 & $118(82.5 \%)$ & $25(17.5 \%)$ & 86.67 & \\
\hline \multirow{2}{*}{ Smoker } & Yes & 98 & $96(98 \%)$ & $2(2 \%)$ & 59.39 & \multirow{2}{*}{$0.016^{*}$} \\
\hline & No & 67 & $44(65.7 \%)$ & $23(34.3 \%)$ & 40.61 & \\
\hline \multirow{2}{*}{$\begin{array}{l}\text { Diabetes } \\
\text { mellitus }\end{array}$} & Yes & 89 & $72(80.9 \%)$ & $17(19.1 \%)$ & 53.94 & \multirow{2}{*}{0.312} \\
\hline & No & 76 & $68(89.5 \%)$ & $8(10.5 \%)$ & 46.06 & \\
\hline \multirow{2}{*}{ Dyslipidaemia $^{\mathrm{b}}$} & Yes & 124 & $108(87.1 \%)$ & $16(12.9 \%)$ & 75.15 & \multirow{2}{*}{$<0.001 *$} \\
\hline & No & 41 & $32(78.0 \%)$ & $9(22.0 \%)$ & 24.85 & \\
\hline
\end{tabular}

${ }^{\mathrm{a}}$ Chi-square test, ${ }^{\mathrm{b}}$ Risk Factor, n: Sample Size, \%: Percentage, BMI: Body Mass Index

Biochemical results for triglycerides, TC, HDL, LDL, PT and INR of the patients were significantly different between the three ethnic groups (Kruskal-Wallis test; p-value < 0.05). The variables which were significantly different were further analyzed using Mann-Whiney tests.

A total of 300 healthy volunteers participated in this study were successfully screened for $C O X-1$ (A-842G), UGT1A6 (A541G and A522C), and $C Y P 2 C 9 * 3(A 1075 C)$ polymorphisms. For $C O X-1$ $(A-842 G)$, no variants were detected in healthy volunteers. Out of the 300 healthy volunteers, 245 and 55 were carriers of wild-type and heterozygous genotypes for $C Y P 2 C 9 * 3$, respectively. No homozygous $C Y P 2 C 9 * 3$ genotype was detected. The genotypes were in Hardy-Weinberg Equilibrium (HWE). The genotype frequencies were significantly different between Indians and Malays as well as between Indians and Chinese; the Indians carry $14 \%$ of $C Y P 2 C 9 * 3$ allele as compared to $2.5 \%$ and $3 \%$ in Malay and Chinese respectively (Table 2). The genotype frequencies for both UGT1A6*2 and *3 among the healthy volunteers 
Table 2. Allele Frequencies of CYP2C9*3 (A1075C), UGT1A6 (*2 \&*3) among the Healthy Volunteers in Three Ethnic Groups

\begin{tabular}{|c|c|c|c|c|c|c|c|c|c|c|c|c|}
\hline \multirow[t]{5}{*}{ Race } & \multicolumn{4}{|c|}{ CYP2C9*3 (A1075C) } & \multicolumn{4}{|c|}{$U G T 1 A 6 * 2(A 541 G)$} & \multicolumn{4}{|c|}{$U G T 1 A 6 * 3(A 522 C)$} \\
\hline & \multirow{2}{*}{\multicolumn{4}{|c|}{$\begin{array}{c}\text { Allele Frequency }(\%) \\
\text { (95\% CI: Lower limit, Upper limit) }\end{array}$}} & \multirow{2}{*}{\multicolumn{4}{|c|}{$\begin{array}{c}\text { Allele Frequency }(\%) \\
\text { (95\% CI: Lower limit, Upper limit) }\end{array}$}} & \multicolumn{4}{|c|}{ Allele Frequency (\%) } \\
\hline & & & & & & & & & \multicolumn{4}{|c|}{ (95\% CI: Lower limit, Upper limit) } \\
\hline & \multicolumn{2}{|c|}{ Wild-type (A) } & \multicolumn{2}{|c|}{ Variant-type $(\mathrm{C})$} & \multicolumn{2}{|c|}{ Wild-type (A) } & \multicolumn{2}{|c|}{ Variant-type (G) } & \multicolumn{2}{|c|}{ Wild-type (A) } & \multicolumn{2}{|c|}{ Variant-type (C) } \\
\hline & $\mathrm{n}$ & Observed & $\mathrm{n}$ & Observed & $\mathrm{n}$ & Observed & $\mathrm{n}$ & Observed & $\mathrm{n}$ & Observed & $\mathrm{n}$ & Observed \\
\hline \multirow[t]{2}{*}{ Malays } & 19 & 97.50 & 5 & 2.50 & 169 & 84.50 & 31 & 15.50 & 155 & 77.50 & 45 & 22.50 \\
\hline & 5 & $(92.26-99.22)$ & & $(0.78-7.74)$ & & $(76.15-90.30)$ & & $(9.70-23.85)$ & & $(68.39-84.58)$ & & $(15.42-31.61)$ \\
\hline \multirow[t]{2}{*}{ Chinese } & 19 & 97.00 & 6 & 3.00 & 171 & 85.50 & 29 & 14.50 & 163 & 81.50 & 37 & 18.50 \\
\hline & 4 & (91.55-98.97) & & $(1.03-8.45)$ & & (77.29-91.09) & & $(8.91-22.71)$ & & $(72.78-87.89)$ & & $(12.11-27.22)$ \\
\hline \multirow[t]{2}{*}{ Indian } & 17 & 86.00 & 28 & 14.00 & 123 & 61.50 & 77 & 38.50 & 102 & 51.00 & 98 & 49.00 \\
\hline & 2 & (77.86-91.47) & & $(8.53-22.14)$ & & $(51.71-70.44)$ & & $(29.56-48.29)$ & & $(41.35-60.58)$ & & $(39.42-58.65)$ \\
\hline
\end{tabular}

were in Hardy-Weinberg Equilibrium (HWE). The genotype frequencies for both UGT1A6 variants were significantly different between Indian and Malay, also Indian and Chinese ethnicity with pvalue less than 0.001 . The frequencies of UGTIA6*2 and *3 were higher in Indian population with $38.50 \%$ and $49.00 \%$, respectively as compared to the Malay $(15.50 \%$ and $22.50 \%$, respectively) and Chinese $(14.50 \%$ and $18.50 \%$, respectively) populations (Table 2). UGT1A6*1 (wild type allele) occurs at frequencies of 0.52 and 0.61 for CVD patients and healthy volunteers of Malay ethnicity. While for the Chinese, the frequencies of the $U G T 1 A 6 * 1$ (wild type allele) for CVD patients and healthy volunteers were 0.56 and 0.64 , respectively. The frequency of the polymorphism of UGTIA6*1 (wild type allele) for the Indians CVD patients was 0.26 whereas the frequency for Indians healthy volunteers was 0.25 . UGT1A6*2/*2 (A541G) and UGT1A6*3/*3 (A522C) was not detected in any ethnic groups. The allelic variants of $U G T 1 A 6 * 2$ and $* 3$ were observed at $20.30 \%$ and $28.18 \%$, respectively in patients with CVD; $22.83 \%$ and $30 \%$, respectively in healthy volunteers. The genotype frequencies of UGTIA6 were similar and consistent in both patients and healthy volunteers. The patients were classified according to different UGTIA6*2 and *3 genotypes and the patients' bilirubin levels show significant differences when compared according to genotypes with p-value less than 0.05 (Table 3).
Table 3. Concentration of Bilirubin with Respect to UGT1A6 $(* 2 \& * 3)$ and $C Y P 2 C 9 * 3$ Genotypes

\begin{tabular}{|c|c|c|c|}
\hline & Genotype & $\begin{array}{c}\text { Bilirubin }^{c} \\
\text { (umol/L) } \\
(\mathrm{n}=164)\end{array}$ & $p$ \\
\hline \multirow{3}{*}{$U G T 1 A 6 * 2$} & $\begin{array}{l}\text { AA (Homozygous } \\
\text { wild-type) } \\
\text { Median (CI: } 95 \% \text { ) }\end{array}$ & $10(9-11)$ & \multirow{3}{*}{$0.045^{*^{\mathrm{a}}}$} \\
\hline & $\begin{array}{l}\text { AG (Heterozygous) } \\
\text { Median (CI: } 95 \% \text { ) }\end{array}$ & $12(9-13)$ & \\
\hline & $\begin{array}{l}\text { GG (Homozygous } \\
\text { variant) } \\
\text { Median (CI: } 95 \%)\end{array}$ & $13(8-21)$ & \\
\hline \multirow{3}{*}{$U G T 1 A 6 * 3$} & $\begin{array}{l}\text { AA (Homozygous } \\
\text { wild-type) } \\
\text { Median (CI: } 95 \% \text { ) }\end{array}$ & $\begin{array}{l}10.0(9.0- \\
11.0)\end{array}$ & \multirow{3}{*}{$0.013^{*^{\mathrm{a}}}$} \\
\hline & $\begin{array}{l}\text { AC (Heterozygous) } \\
\text { Median (CI: } 95 \% \text { ) }\end{array}$ & $\begin{array}{l}11.0(9.0- \\
13.0)\end{array}$ & \\
\hline & $\begin{array}{l}\mathrm{CC} \text { (Homozygous } \\
\text { variant) } \\
\text { Median (CI: } 95 \%)\end{array}$ & $\begin{array}{l}13.5(10.0- \\
19.0)\end{array}$ & \\
\hline \multirow{2}{*}{$C Y P 2 C 9 * 3$} & $\begin{array}{l}\text { AA (Homozygous } \\
\text { wild-type) } \\
\text { Median (CI: } 95 \% \text { ) }\end{array}$ & $10(9-11)$ & \multirow[b]{2}{*}{$0.643^{\mathrm{b}}$} \\
\hline & $\begin{array}{l}\text { AC (Heterozygous) } \\
\text { Median (CI: } 95 \% \text { ) }\end{array}$ & $13(8-15)$ & \\
\hline \multicolumn{4}{|c|}{$\begin{array}{l}\text { a }{ }^{\mathrm{a}} \text { Kruskal-Wallis test, }{ }^{\mathrm{b}} \text { Mann-Whitney test, }{ }^{\mathrm{c}} \text { Laboratory data, } \\
\text { N: Sample Size, Cl: Confident Interval } * \text { Statistical } \\
\text { significance }(P \text {-value }<0.05) \text {, AA: Homozygous wild-type, } \\
\text { AG: Heterozygous, GG: Homozygous variant, AC: } \\
\text { Heterozygous, CC: Homozygous variant. }\end{array}$} \\
\hline
\end{tabular}


The association between genotype and gastritis event among patients who took aspirin as their anticoagulant drug were calculated using chisquare test. The odds ratio (OR) was used to examine the risk of each genotype in association with the development of gastritis event. Referring to the odds ratios in Table 4, individual who were heterozygous CYP2C9* 3 genotype shows 6.8 times more likely to have gastritis when compared to the individual with homozygous wild-type.

Table 4. Odd Ratios of Gastritis in Aspirin Treated Patients with Different Genotypes of UGT1A6 (*2 \&*3) and $C Y P 2 C 9 * 3$.

\begin{tabular}{|c|c|c|c|c|c|}
\hline \multirow[b]{2}{*}{ Gene } & \multirow[b]{2}{*}{ Genotype } & \multicolumn{2}{|c|}{ Gastritis } & \multirow[b]{2}{*}{$\begin{array}{c}\text { OR } \\
\text { (CI: } 95 \%)\end{array}$} & \multirow[b]{2}{*}{$P$} \\
\hline & & $\begin{array}{c}\text { With Event } \\
\text { N\% }\end{array}$ & $\begin{array}{c}\text { Without Event } \\
\text { N\% }\end{array}$ & & \\
\hline \multirow{3}{*}{$U G T 1 A 6^{*} 2$} & AA (Homozygous Wild-Type) & 7.69 & 92.31 & \multirow{3}{*}{$\begin{array}{c}2.8 \\
(1.35-5.57)\end{array}$} & \multirow{3}{*}{0.776} \\
\hline & AG (Heterozygous) & 5.41 & 94.60 & & \\
\hline & GG (Homozygous Variant) & 0.00 & 100.00 & & \\
\hline \multirow{3}{*}{$U G T 1 A 6 * 3$} & AA (Homozygous Wild-Type) & 4.84 & 95.16 & \multirow{3}{*}{$\begin{array}{c}2.3 \\
(1.19-4.61)\end{array}$} & \multirow{3}{*}{0.360} \\
\hline & AC (Heterozygous) & 9.43 & 90.57 & & \\
\hline & CC (Homozygous Variant) & 0.00 & 100.00 & & \\
\hline \multirow{2}{*}{$\begin{array}{c}C Y P 2 C 9 * 3 \\
(A 1075 C)\end{array}$} & AA (Homozygous Wild-Type) & 4.67 & 95.33 & \multirow{2}{*}{$\begin{array}{c}6.8 \\
(1.39-33.19)\end{array}$} & \multirow{2}{*}{$0.033^{*}$} \\
\hline & AC (Heterozygous) & 25.00 & 75.00 & & \\
\hline
\end{tabular}

Table 5. Analysis of linkage disequilibrium of $U G T 1 A \sigma^{*} 2$ and $U G T 1 A 6^{*} 3$ in Malaysian Population

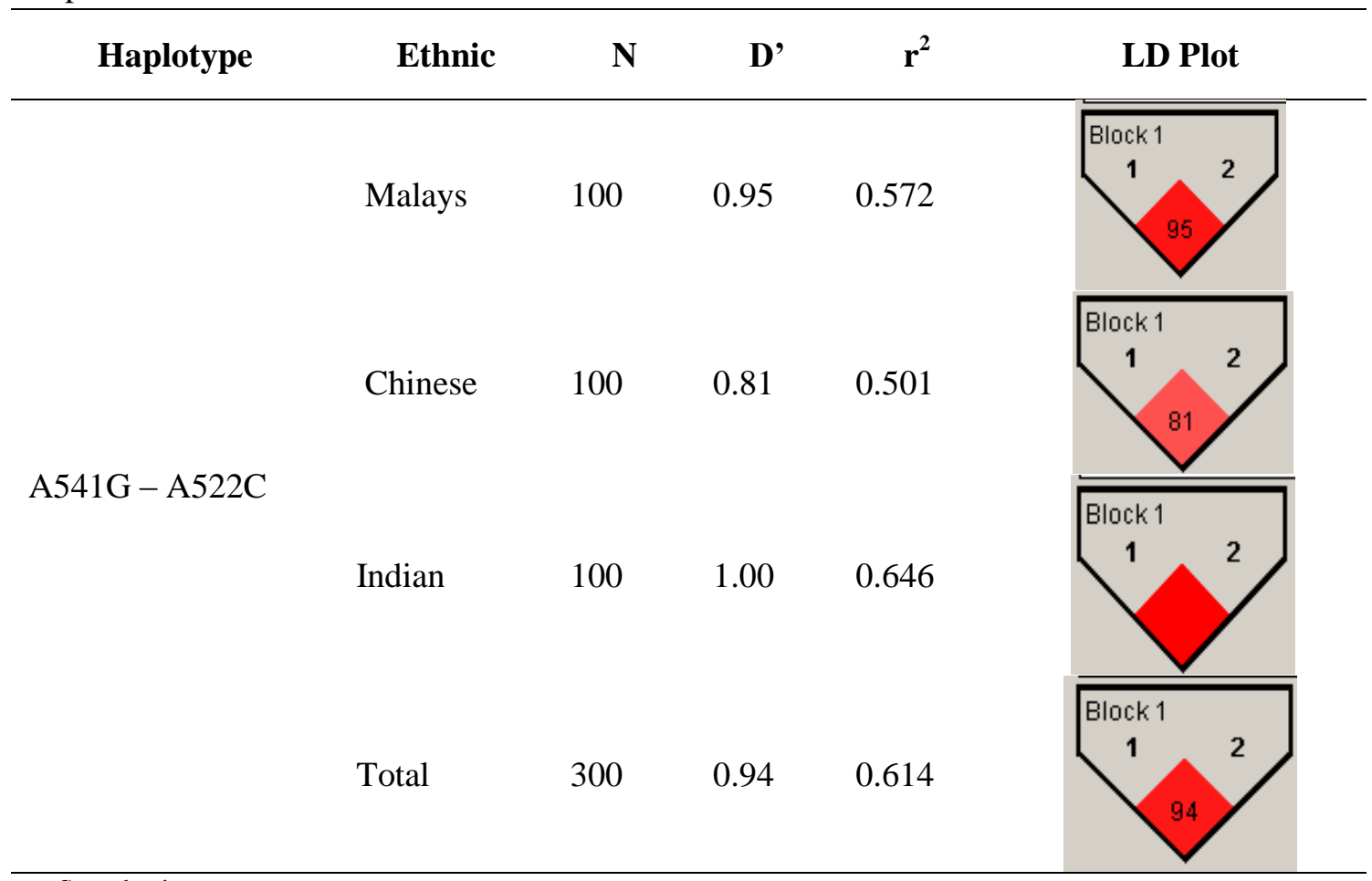

n: Sample size 


\begin{abstract}
Haplotypes was analysed using haploview which was downloaded from http://www.broadinstitute.org/haploview. This software was used to observe the linkage between two UGT1A6 variants (*2 and *3). This analysis was done for the three major ethnic groups in Malaysian population which are the Malays, Chinese and Indians. A hundred samples from each ethnic group were used to study the degree of linkage between the three ethnic groups. As shown in Table 5, Indians have a strong degree of linkage disequilibrium with $D^{\prime}$ value of 1 . Both variants were found in different percentage of linkage disequilibrium for different ethnic groups, which are $95 \%, 81 \%$ and $100 \%$ in Malay, Chinese and Indian ethnic groups, respectively (Table 5).
\end{abstract}

\section{DISCUSSION}

Most of the smokers were males and this is in line with the high number of male smokers (2.61 million) in Malaysia compared to 120,000 female smokers $[13,14]$. The latest projections indicate that approximately 3.1 million smokers were between 25 and 64 years in Malaysia. The Malays constitute the largest number of smokers in Malaysia, with $60.9 \%$ [15]. This situation might provide one of the reasons why the Malays tends to have higher incidences of CVD at earlier age compared to the Chinese.

Among 165 patients with CVD in this study, $86.67 \%$ were overweight and $75.15 \%$ have dyslipidemia. Singh et al. [16] have suggested that obesity and dyslipidemia are related and play major roles in the development of CVD. In addition, this study also showed that there was a significant difference in the lipid profile between the Malays and two other ethnic groups, which was in agreement with the results of Khoo et al. [17]. Further, there was also a significant association between body weight and ethnicity $(p=0.007)$, where the BMI of the Malays were higher. This finding is supported by Malaysia's National Health and Morbidity Survey $2(1996$ - 1997) which found that obesity was significantly associated with ethnicity. This observation may be explained by differences in dietary habits or lifestyle, or by genetic factors between the three ethnic groups.

PT and INR values of the Malay patients were found to be significantly different when compared with the values observed in the Indian and Chinese ( $p$ values of 0.016 and 0.014 , respectively). The differences of PT and INR may be affected by daily diet. According to Rombout et al. [18], an increase in the amount of food rich in vitamin $\mathrm{K}$ can lower the PT and INR of an individual. Green and leafy vegetables such as broccoli, lettuce and spinach are part of the routine diet of the Chinese ethnic group in Malaysia and therefore it is not surprising for the Chinese to have lower PT and INR values [19].

Halushka et al.[20] have found that heterozygocity of $C O X-1 \quad(A-842 G)$ gene significantly shows greater inhibition in the formation of prostaglandin $\mathrm{H}_{2}$ by acetylsalicylic acid compared with common homozygous wildtype allele. Unfortunately this variant is not detected in this study, even though it was detected at a high percentage among the Caucasians (19\% heterozygous and $1 \%$ homozygous) [20,5].

Nagar et al., (2004) reported that the frequencies of $U G T 1 A 6 * 2$ and $U G T 1 A 6 * 3$ were $5.7 \%$ and $5.2 \%$ in Caucasian and, $10 \%$ and $5 \%$ in African-American [21]. The percentage frequency of $U G T 1 A \sigma^{*} 2$ and $U G T 1 A \sigma^{*} 3$ for the Chinese population in China were $22 \%$ and $24.7 \%$, respectively [22]. Similarly, in the Japanese, $U G T 1 A 6 * 2$ and $U G T 1 A 6 * 3$ were present in $21.8 \%$ and $2.26 \%$, respectively in the population, [23]. Limenta et al.[24] reported that UGTIA6 variants were found in $19 \%$ of the Thailand population. The percentage of UGTIA6 variants reported in this study was somewhat consistent with findings among the Chinese in China and Japanese population. Both variants of UGTIA6 were reported to be in complete linkage-disequilibrium of $>98 \%$ [5]; while in this study, the linkage was found to be $94 \%$.

The significant association between the concentration of the patients' bilirubin and $U G T 1 A 6 * 2$ and $* 3$ was in accordance with a previous finding by Peters et al.[25]. From the existing evidence, the concentration of bilirubin in patients with CVD was associated with the enzyme activity of UGTIA6. As shown in our results, higher concentration of bilirubin was found in patients who possess variants allele of UGT1A6 with slow metabolizing capacity. In other studies by Djousse et al. [26] and Lin et al. [27], high levels of bilirubin was associated with decreased risks of coronary heart disease (CHD) and cardiovascular disease (CVD). Similarly in the Framingham 
Offspring Study, higher serum bilirubin concentrations were associated with decreased risk of CVD, CHD, and myocardial infarction (MI) [28]. The association between the genetic polymorphisms of UGTIA6 and the concentration of bilirubin are interesting finding and a case-control study with longer follow-up time might be useful to confirm the relationship.

Homozygous genotype of $C Y P 2 C 9 * 3$ was reported to present at low frequency of only $1 \%$ in the Malay and Indian population [29], but no homozygous $C Y P 2 C 9 * 3$ was found in this study. There were also no subjects with homozygous CYP2C9*3 in the 115 Han Chinese as well as 218 Japanese and 98 Taiwanese [30-32]. The genotype frequency of $C Y P 2 C 9 * 3$ in this study is in agreement with the reported rare frequency in most population worldwide.

Similar with findings from Van Oijen et al.[5], no significant association between the occurrence gastric events and polymorphisms of UGT1A6 gene in aspirin treated patients were detected. However, there was a significant association between the slow metabolizer (SM) of heterozygous $C Y P 2 C 9 * 3$ with the gastritis events among the CVD patients treated with aspirin. There were $25 \%$ occurrences of gastritis in patients with heterozygous $C Y P 2 C 9 * 3$ while only $4.67 \%$ of gastric event among patients with homozygous wild type. Martin et al., [33] revealed that $30 \%$ of NSAID treated subjects experienced ulceration event in non-wild type CYP2C9 genotypes. The calculated odd ratios (OR) in this study indicated that individuals who were taking aspirin and with heterozygous $C Y P 2 C 9 * 3$ genotype have 6.8 times higher risk to get gastritis as compared to the individual with homozygous wild-type ( $p$-value 0.033).

\section{CONCLUSION}

In conclusion, we have successfully developed allele specific PCR (AS-PCR) methods for detection of COX-1 (A-842G), UGT1A6*2 and *3 and $C Y P 2 C 9(A 1075 C)$ alleles. Besides, we also have successfully genotyped all the 165 patients and 300 healthy volunteers.

There was an association between the bilirubin concentration of CVD patients and variants of $U G T 1 A 6 * 2$ and $* 3$ gene. In addition, this study also found an association of $C Y P 2 C{ }^{*} 3$ variant allele (slow metabolizer of aspirin) with the occurrence of gastritis event among CVD patients treated with aspirin.

This study provides support to recommend genotyping of CVD patients for UGTIA6*2 and *3 and $C Y P 2 C 9 * 3$. However, further studies are needed to confirm the association between the genetic polymorphisms of UGT1A6 with the concentration of bilirubin. A case-control study with longer follow-up period might be useful to provide answers to the relationship. In addition, the potential of bilirubin as therapeutic target or tool in monitoring the disease of CVD patients, a clear cut-off concentration or range of normal bilirubin concentration need to be established. Case controlled studies using bigger sample size is required.

\section{ACKNOWLEDGMENTS}

The project is funded by Ministry of Education Malaysia (UiTM 600 RMI/ST/FRGS 5/3/FST $(63 / 2010))$. The authors thank all the subjects that had contributed to the project.

\section{REFERENCES}

1. Baigent C, Sudlow C, Collins R, Peto R. Collaborative meta-analysis of randomised trials of antiplatelet therapy for prevention of death, myocardial infarction, and stroke in high risk patients. British Medical Journal 2002; 324(7329): 71-86.

2. Eikelboom JW, Hirsh J, Weitz JI, Johnston M, Yi Q, Yusuf S. Aspirin-resistant thromboxane biosynthesis and the risk of myocardial infarction, stroke, or cardiovascular death in patients at high risk for cardiovascular events. Journal of The American Heart Association: Circulation 2002; 105: 16501655.

3. Agúndez JAG, Martínezl C, Pérez-Sala D, Carballo M, Torres MJ, García-Martí E. Pharmacogenomics in aspirin intolerance. Drug Metabolism 2009; 9981008.

4. Lampe JW, Bigler J, Horner, NK, Potter JD. UDPglucuronosyltransferase (UGT1A1*28 and UGT1A6*2) polymorphisms in caucasians and asians: relationships to serum bilirubin concentrations. Pharmacogenetics 1999; 9(3): 341349.

5. van Oijen MGH., Huybers S, Peter WHM, Drenth JPH, Leheij RJF, Verheugt FWA, Jansen JBM. Polymorphisms in genes encoding acetylsalicylic 
acid metabolizing enzymes are unrelated to upper gastrointestinal health in cardiovascular patients on acetylsalicylic acid. Journal of The British Clinical Pharmocology 2005; 60(6): 623-628.

6. Bigler J, Whitton J, Lampe JW, Fosdick L, Bostick RM, Potter, JD. CYP2C9 and UGT1A6 genotypes modulate the protective effect of aspirin on colon adenoma risk. Journal of Cancer Research 2001; 61(9): 3566-3569.

7. Martinez C, Blanco G, Ladero JM, Garcia-Martin E, Taxonera C, Gamito FG, Diaz-Rubio M, Agundez JA. Genetic predisposition to acute gastrointestinal bleeding after NSAIDs use. Journal of British Pharmacology 2004; 141: 205-208.

8. Blanco G, Martínez C, Ladero JM, Garcia-Martin E, Taxonera C, Gamito FG, Diaz-Rubio M, Agundez JA. Interaction of CYP2C8 and CYP2C9 genotypes modifies the risk for nonsteroidal antiinflammatory drugs-related acute gastrointestinal bleeding. Pharmacogenetics Genomics 2008; 18: 37-43.

9. Hopkins PN, Wu LL, Hunt SC, James BC, Vincent GM and Williams RR. Higher serum bilirubin is associated with decreased risk for early familial coronary artery disease. Journal of The American Heart Association: Arteriosclerosis, Thrombosis, and Vascular Biology 1996; 16: 250-255.

10. Teh LK, Ismail R, Yusoff R, Hussein A, Isa M, \& Rahman AR. Heterogeneity of the CYP2D6 gene among Malays in Malaysia. Journal of Clinical Pharmacy and Therapeutics 2001; 126, 205-211.

11. Gaudet M, Fara AG, Beritognolo I, Sabatti M. Allele-specific PCR in SNP genotyping. Method in Molecular Biology 2009; 579: 415-424.

12. Chen B, Wilkening S, Drechse M, Hemminki K. SNP_tools: A compact tool package for analysis and conversion of genotype data for MS-Excel. $B M C$ Research Note 2009; 2: 214.

13. National Health Morbidity Survey-Diabetes. Institute for Public Health, Ministry of Health, Malaysia 2006.

14. Quek DKL, Urn LY, Blong S. Cigarette smoking and the risk of myocardial infarction, and acute noninfarct coronary events among Malaysian women. Journal of Medical Malaysia 1989; 44: 3.

15. Andrew KGT, Steven TY, Rodolfo M, Nayga Jr. Role of education in cigarette smoking: an analysis of Malaysian household survey data. Asian Economic Journal 2007; 23 (1): 1-17.

16. Singh AK, Singh SK, Singh N, Agrawal N, Gopal $\mathrm{K}$. Obesity and dyslipidemia. International Journal of Biological \& Medical Research 2011; 2(3): 824828.

17. Khoo KL, Tan H, Liew YM. Serum lipids and their relationship with other coronary risk factors in healthy subjects in a city. Clinical Medical Journal
Malaysia 1997; 52: 38-52.

18. Rombouts EK, Rosendaal FR, Van Der Meer FJ. Daily vitamin $\mathrm{K}$ supplementation improves anticoagulant stability. Journal of Thrombosis and Haemostasis 2007; 5: 2043-2048.

19. Fiumara K, Goldhaber SZ. A patient's guide to taking coumadin/warfarin. Circulation 2009; 119: 220-222.

20. Halushka MK, Walker LP, Halushka PV. Genetic variation in cyclooxygenase 1: effects on response to aspirin. Clinical Pharmacology and Therapeutics 2003; 73(1):122-130.

21. Nagar S, Zalatoris JJ, and Blanchard RL. Human UGT1A6 pharmacogenetics:identification of a novel SNP, characterization of allele frequencies and functionalanalysis of recombinant allozymes in human liver tissue and in cultured cells. Pharmacogenetics 2004; 14: 487- 499.

22. Xing Y, Yang L, Wang L, Shao L, Wei Z, Xuan J, Li J, Qin S, Shu A, He L, Xing Q. Systematic screening for polymorphisms within the UGT1A6 gene in three Chinese populations and function prediction through structural modelling. Journal of Pharmacogenomics, 2009; 10: 741-752.

23. Saeki M, Saito Y, Jinno H, Sai K, Kaniwa H, Kamakura S, Kitakaze M, Tomoike H, Shirao K, minami H, Ohtsu A, Yoshida T, Saijo N, Kamatani N, Sawada J. Genetic polymorphisms of UGT1A6 In japanese population. Journal of Drug Metabolisms Pharmacokinetic 2005; 20(10): 85-90.

24. Limenta LMG, Jirasomprasert $\mathrm{T}$, Morales NP. UGT1A6 genotype-related pharmacokinetics of deferiprone (L1) in healthy volunteers. Journal of the British Pharmacology 2008; 65(6): 908-916.

25. Peters WHM, Rene, HM, te Morsche, Roelofs HMJ. Combined polymorphisms in UDPglucuronosyltransferases 1A1 and 1A6: implications for patients with Gilbert's syndrome. Journal of Hepatology 2003; 38: 3-8.

26. Djousse L, Levy D, Cupples LA, Evans JC, D'Agostino RB, Ellison RC. Total serum bilirubin and risk of cardiovascular disease in the Framingham offspring study. Journal of Cardiology 2001; 87:11.

27. Lin JP. Association between the UGT1A1*28 allele, bilirubin levels, and coronary heart disease in the Framingham Heart Study. Circulation 2007; 114(14): 1476-1481.

28. Öllinger R, Bilban M, Erat A, Froio A, McDaid J, Tyagi S, Csizmadia E,Graca-Souza AV, Liloia A, Soares MP, Otterbein LE, Usheva A,Yamashita K, Bach FH. Bilirubin: a natural inhibitor of vascular smooth muscle cell proliferation. Circulation 2005; 112: 1030-1039.

29. Seng CK, Gin GG, Sangkar JV, Phipps ME. Frequency of cytochrome P450 (CYP2C9) allele in 
three ethnic groups in Malaysia. Journal of Asia Pacific: Molecular Biology and Biotechnology 2003; 11(2): 83-91.

30. Wang SL, Huang JD, Lai MD, Tsai JJ. Detection of CYP2C9 polymorphims based on the polymerase chain reaction in Chinese. Journal of Pharmacogenetics 1995; 5: 37-42.

31. Sullivan-Klose TH, Ghanayem BI, Bell DA, Zhang, ZY, Kaminsky LS, Shenfield GM, Miner JO, Birkett DJ, Goldstein JA. The role of the CYP2C9-Lue 359 allelic variant in the tolbutamide polymorphism. Journal of Pharmacogenics 1996; 6: 341-349.

32. Nasu K, Kubota T, Ishizaki T. Genetic analysis of CYP2C9 polymorphims in a Japanese population. Pharmacogenetics 1997; 7: 405-409.

33. Martin JH, Begg EJ, Kennedy MA, Roberts R, and Barclay ML. Is cytochrome P450 2C9 genotype associated with NSAID gastric ulceration? British Journal of Clinical Pharmacology 2001; 51:627630. 